\title{
Interferência fotográfica
}

\section{Photographic interference}

Lorie Novak ${ }^{1}$

(Tradução: José Yoshitake)

\section{Resumo}

A interferência fotográfica é um projeto baseado em fotos que explora nossa situação contemporânea em que as imagens fotográficas e reportagens nos assaltam e sub-repticiamente nos envolvem. Baseia-se no meu trabalho anterior e em sua relação com a memória e transmissão: como fotografias afetam a forma como sabemos o que sabemos, como lembranças pessoais e recordações culturais se cruzam, como fotografias influenciam a narrativa e a história, e como a nossa relação com a mídia afeta nossos modos de saber. Interferência Fotográfica traz minha coleção de seções de notícias do The New York Times de 01 de abril de 1999 até o presente.

Palavras-chave: Fotografia, Mídia, Performance.

\begin{abstract}
Photographic Interference is a photo-based project exploring our contemporary predicament in which photographic images and news reports assault us and surreptitiously envelop us. It builds upon my previous work and interest in memory and transmission: how photographs affect how we know what we know, how personal remembrances and cultural recall intersect, how photographs influence storytelling and history, and how our relationship to media affects our ways of knowing. Photographic Interference draws from my collection of news sections from The New York Times from April 1, 1999 to the present.
\end{abstract}

Keywords: Photography, Media, Performance.

1 Lorie Novak, é artista e Professora de Fotografia \& Visualização na Tisch School of the Arts, New York University e Membro de The Hemispheric Institute of Performance and Politics. Veja www.lorienovak.com para mais informações. 


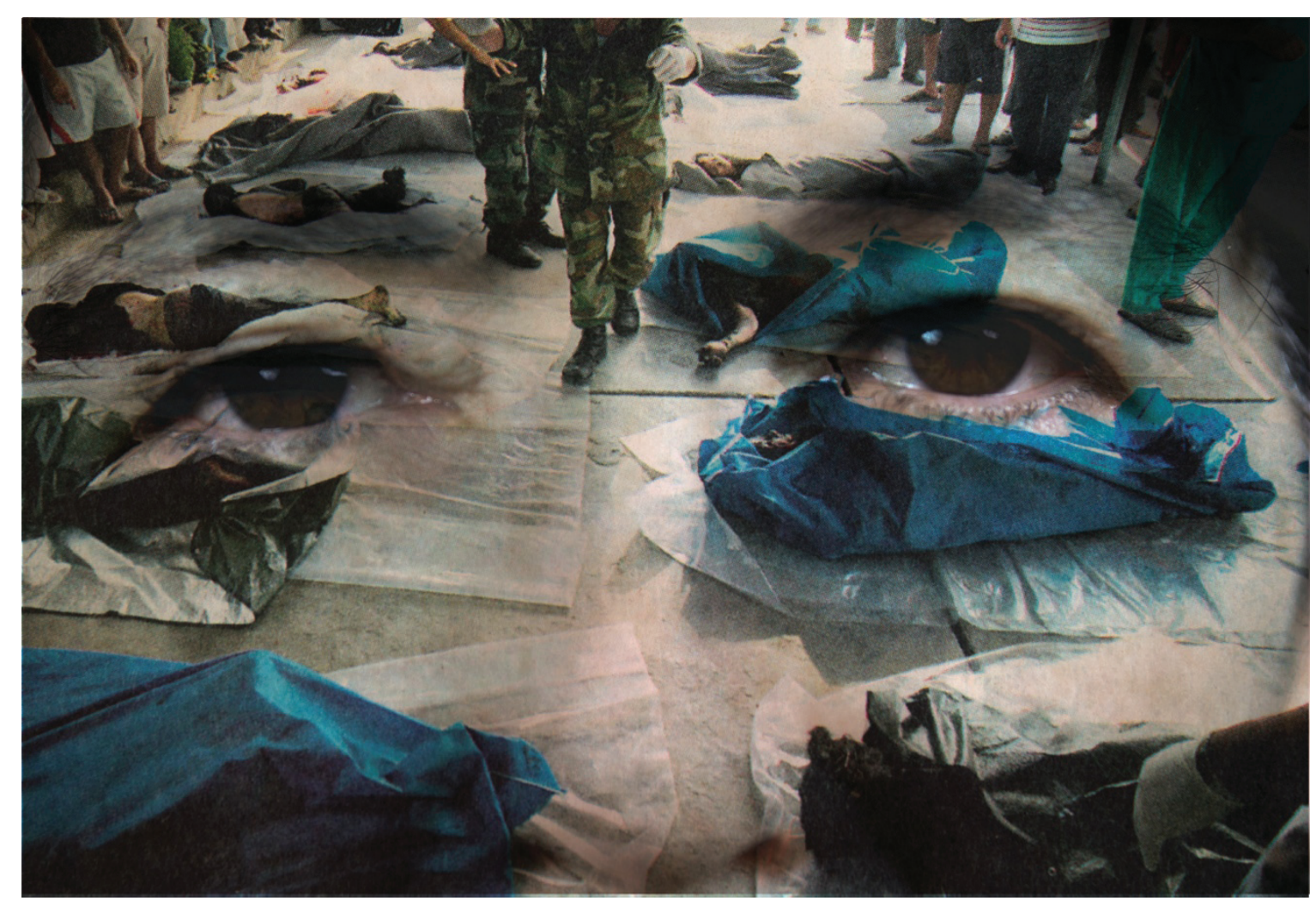

Bodies, 2012

Fotografias de atrocidades estão em todo lugar. É difícil olhar, mas igualmente difícil afastar o olhar. Como uma artista, não posso ignorar estas imagens — elas penetram em mim. Minha série Interferência Fotográfica explora o pós-vida de imagens e da experiência de olhar fotografias como um encontro disruptivo. Quero causar uma ruptura em nossas expectativas e dialogar com nossos tempos difíceis, confusos e perigosos nos quais a mídia e a fotografia têm simultaneamente perdido credibilidade e ganhado autoridade. 


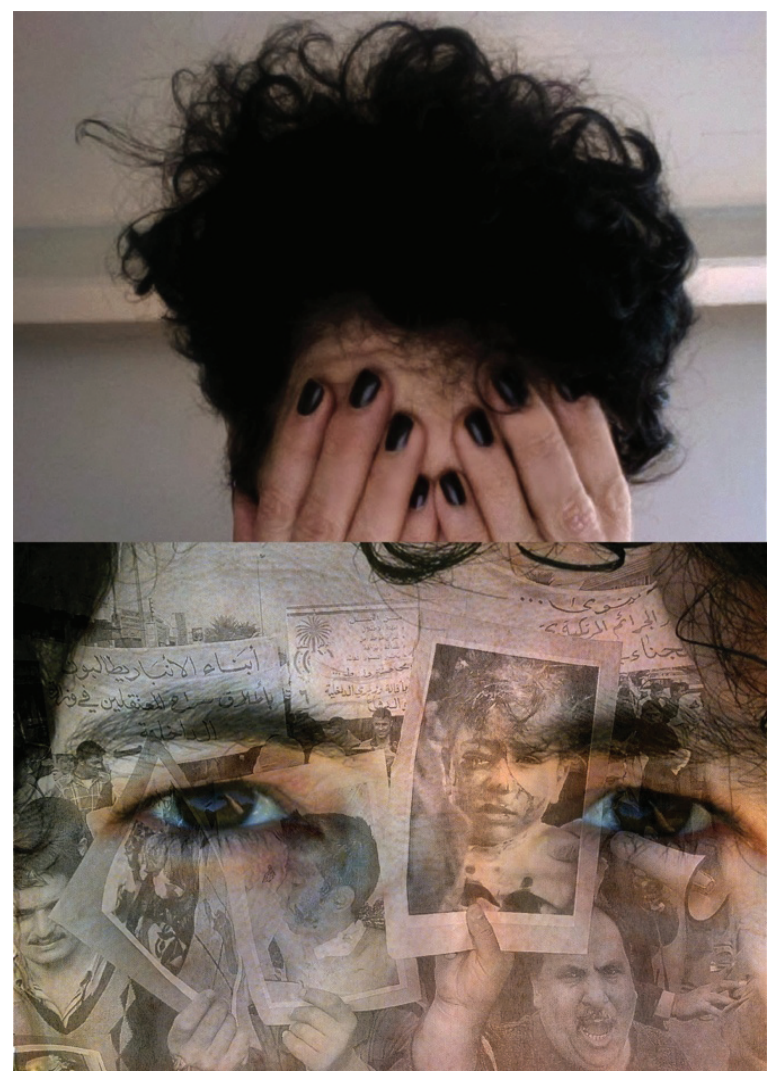

Look/Not/Look, 2011

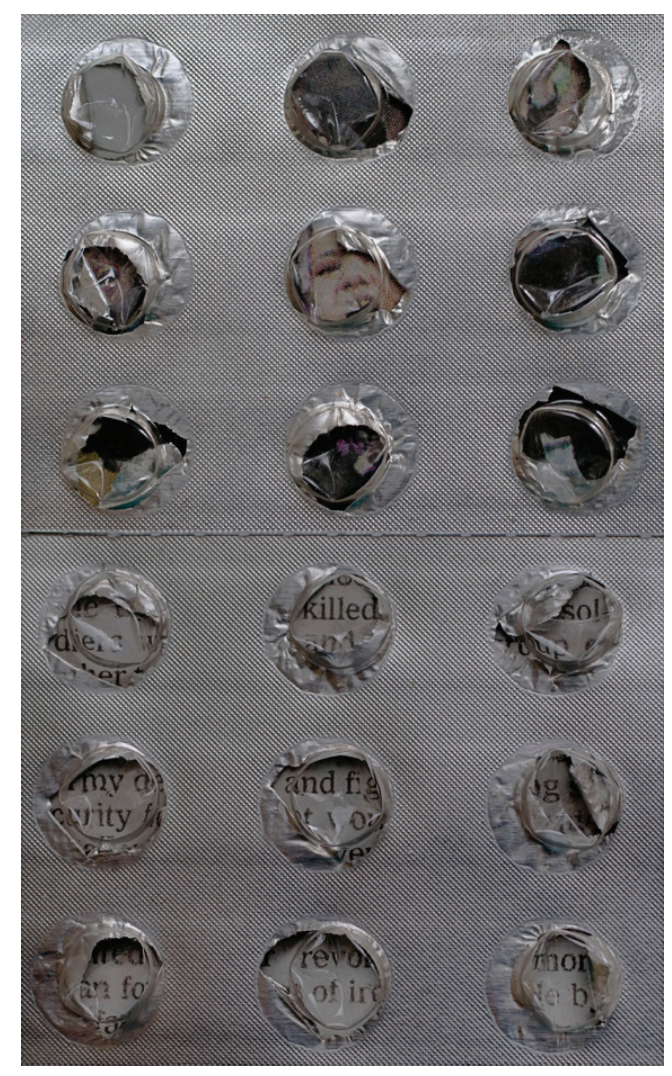

Medicated, 2011

O projeto se baseia em meu contínuo interesse em memória e transmissão: como as fotografias afetam o que somos e o que sabemos, como lembranças pessoais e recordações culturais se intersecionam, como as fotografias influenciam o narrar e a história, e como nosso relacionamento com a internet afeta nossas formas de saber. O alicerce de Interferência Fotográfica é minha coleção já com 15 anos e ainda em andamento de aproximadamente 5.500 seções de notícias do New York Times. Eu comecei guardando a seção de capa do New York Times em março de 1999, quando a OTAN começou a bombardear a Sérvia durante a Guerra de Kosovo. Minha ideia era ter uma pilha de jornais que significavam uma guerra. Quando o cessar-fogo foi assinado, uma resolução verdadeira não foi alcançada, por isso continuei colecionando. $O$ World Trade Center foi atacado, e continuei colecionando. Eu não parei. 


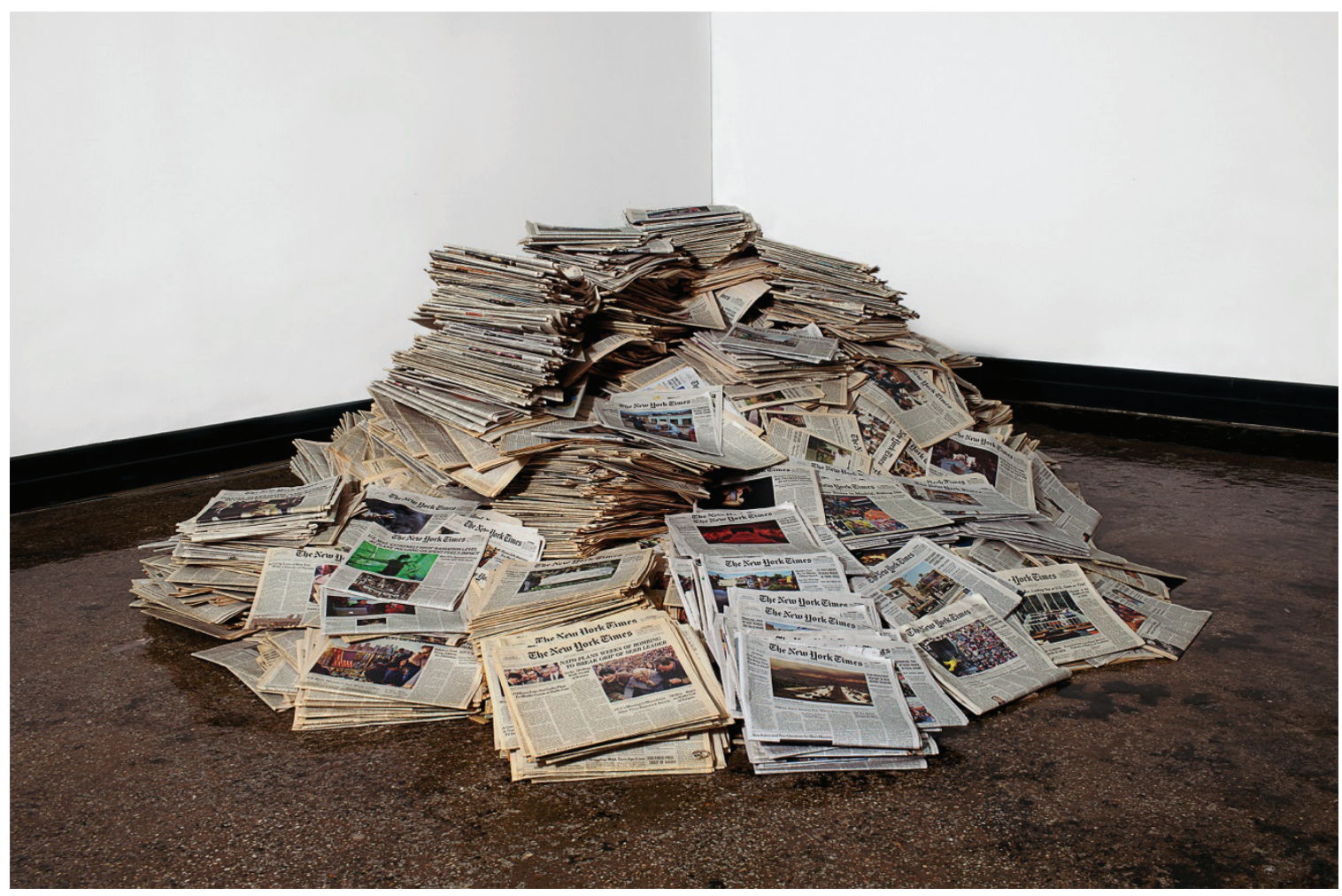

New York Times, April 1, 1999 - September 7, 2011

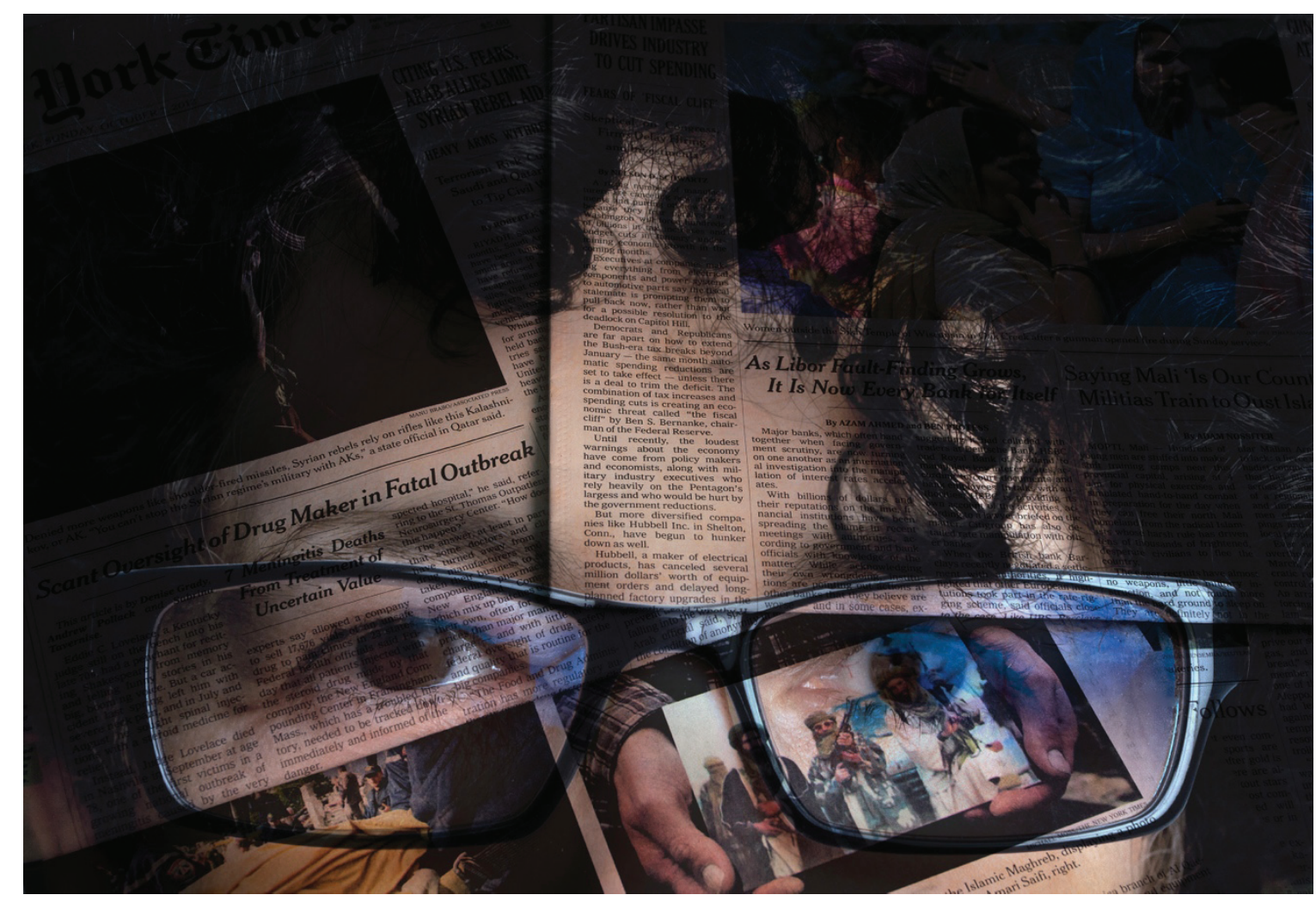

Fore Eyes, 2012 
Eu fotografo fragmentos das capas, assim como os jornais, em pilhas, em pilhas bagunçadas, como objetos que eu seguro e toco. Eu puxo imagens para fora da Web. Eu incorporo meu olhar às imagens, analogamente ao modo pelo qual, com frequência, somos capazes de ver nossa imagem refletida quando olhamos imagens no computador. Estas intervenções rompem com e interferem em nossa percepção e compreensão, chamam atenção para o ato de olhar, conectam o pessoal com o político, e quebram nossa distância emocional com o passado. Eu sou tanto uma fazedora de imagens quanto uma consumidora.

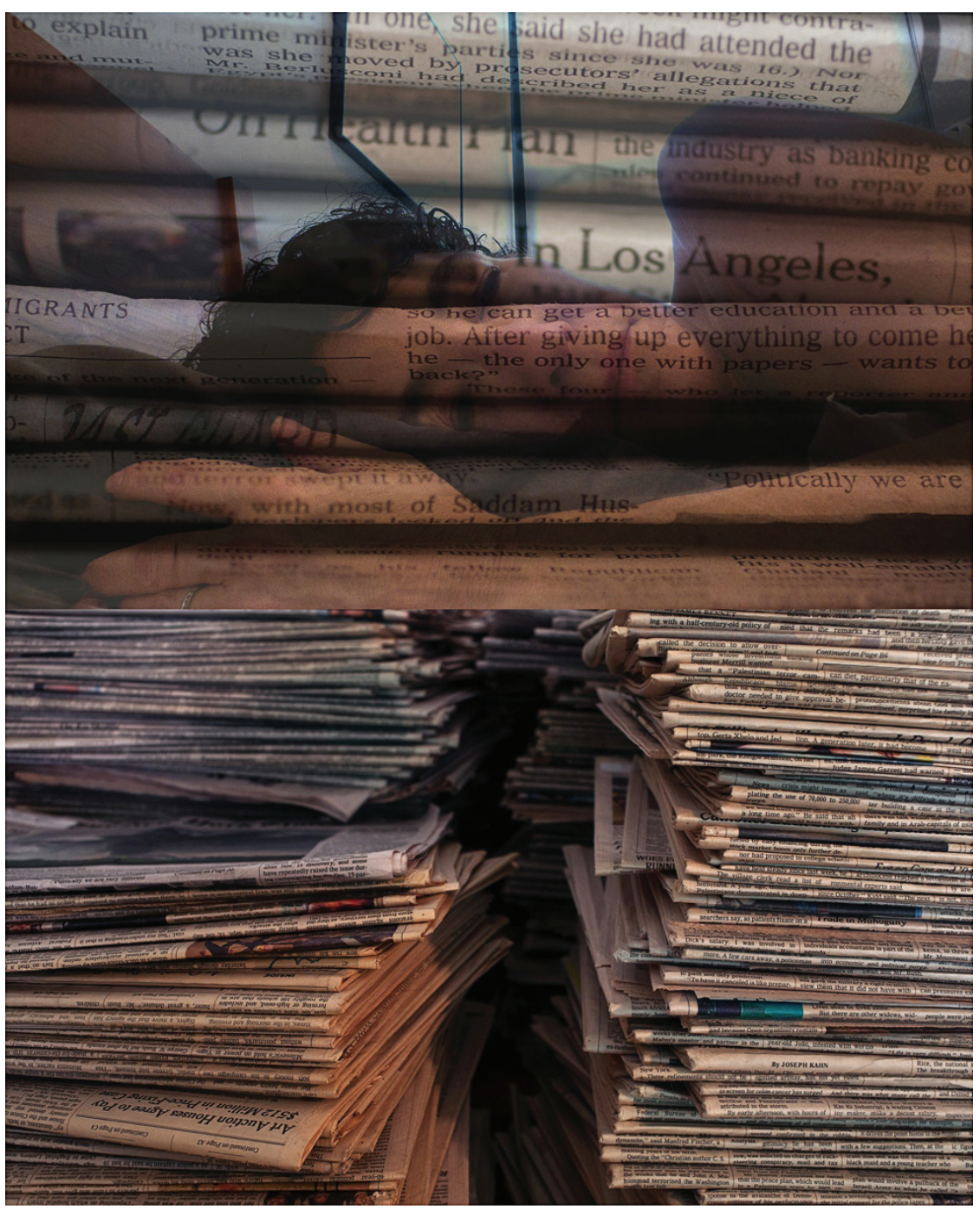

In Los Angeles, 20111 


\section{Referências}

HIRSCH, Marianne; NOVAK, Lorie. Family Projections: Lorie Novak in conversation with Marianne Hirsch. Family Politics, Issue 20, Photoworks Annual. Brighton: England, 2013.

NOVAK, Lorie. Photographic Interference, in Picturing Atrocity edited by Geoffrey Batchen, Mick Gidley, Nancy K. Miller, Jay Prosser. London: Reaktion Books, 2012

WEXLER, Laura. Instilling Interference, e-misférica 9.1-9.2: On the Subject of Archives edited by Marianne Hirsch and Diana Taylor. Essay accompanies Lore Novak's multimedio, Random Interference, 2012. Disponíve em http://hemisphericinstitute.org/hemi/en/e-misferica-91 (acesso em 10/03/2014)

WOLTHERS, Louise. Virtual Selves: Art and Digital Autobiography in Digital Snaps: The New Face of Photography, edited by Jonas Larsen and Mette Sandbye. London: I.B. Tauris, 2014

\section{Photos}

Bodies, 2012, ink jet print (exhibition size: 20×30")

Look/Not/Look, 2011, ink jet print (exhibition size: 40"x28.6")

Medicated, 2011, ink jet print (exhibition size: 40x24.4")

Fore Eyes, 2012, ink jet print (exhibition size: 20x30")

In Los Angeles, 2011, ink jet print (exhibition size: 40 x 32.4")

(Newspaper Pile)

April 1, 1999 - September 7, 2011, ink jet print (exhibition size: 30x45")

Recebido em 17/03/2014

Aprovado em 30/04/2014

Publicado em 25/06/2014 